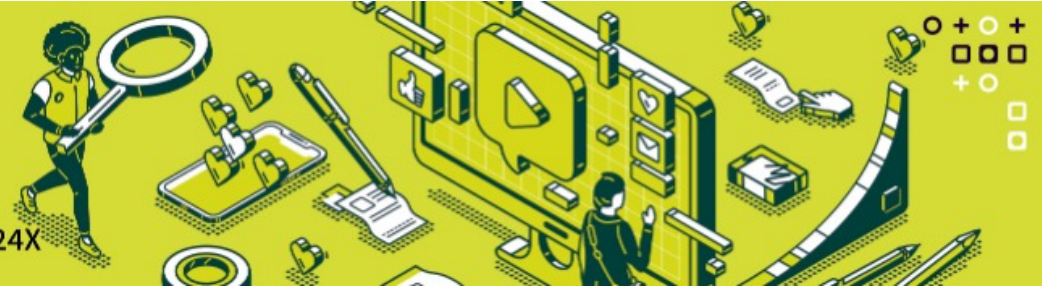

\title{
MEMÓRIAS E PROCESSO CRIATIVO NO ENSINO DE ARTES VISUAIS: APONTAMENTOS METODOLÓGICOS EM TEMPOS DE PANDEMIA
}

\author{
MEMORIES AND CREATIVE PROCESS IN VISUAL ARTS TEACHING: METHODOLOGICAL NOTES IN TIMES OF PANDEMIC
}

${ }^{1}$ Diêmille Santos da Silva; ${ }^{2}$ Valter Mesquita

\author{
${ }^{1}$ Universidade Federal do Amazonas - diemillesantos@gmail.com \\ ²Universidade Federal do Amazonas - valtermesquita@ufam.edu.br
}

\begin{abstract}
RESUMO: O presente artigo trabalhar com as categorias analíticas referentes a memória, experiência e velhice a partir das memórias dos avós dos discentes que cursam o ensino fundamental II, para dar base para o desenvolvimento da atividade proposta com eles. Foram selecionados dois alunos de cada série dos anos finais para desenvolverem um processo criativo em kirigami em meio a conjuntura pandêmica e ensino remoto. A ação interventiva trabalhará com a metodologia da história oral e fará uso de entrevistas via utilização de roteiro semiestuturado. $O$ objetivo consiste em analisar a releitura das obras da artista Hadna Abreu, a partir das produções pelos alunos de peças autorais (kirigami), tomando as obras da artista como base, viabilizando nesse processo o desenvolvimento da criatividade e proximidade entre os membros mais velhos e os mais novos da família.
\end{abstract}

PalaVRAS-CHAVE: Memórias, Experiência, Velhice, Processo Criativo, Kirigami.

ABSTRACT: This article aims to work with the analytical categories referring to memory, experience and old age from the memories of the grandparents of students attending elementary school II, to provide a basis for the development of the proposed activity with them. Two students from each grade of the final years were selected to develop a creative process in kirigami amid the pandemic situation and remote teaching. The interventional action will work with the methodology of oral history and will make use of interviews using a semi-structured script. The objective is to analyze the re-reading of the works of the artist Hadna Abreu, from the productions by students of copyright pieces (kirigami), taking the artist's works as a basis, enabling in this process the development of creativity and proximity between older members and the youngest in the family.

KEYWORDS: Memories, Experience, Old Age, Creative Process, Kirigami. 


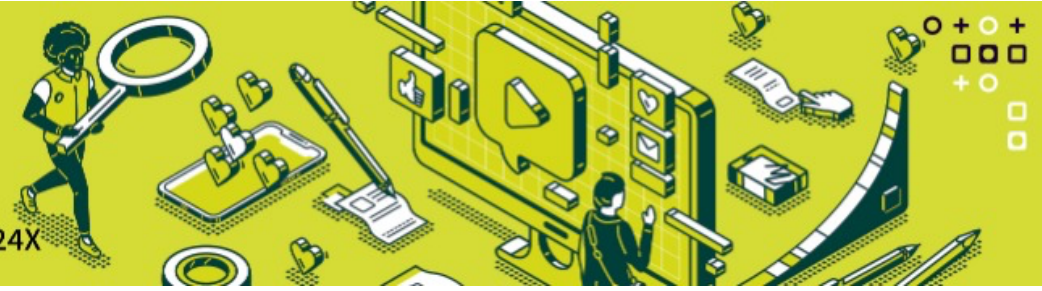

\section{INTRODUÇÃo}

Este artigo é fruto de uma pesquisa em andamento no âmbito do Mestrado Profissional em Artes PROFARTES, que resultou na construção de uma abordagem metodológica a partir de aproximações entre conceitos e métodos para o ensino das artes visuais. A proposta pedagógica está sendo aplicada em um grupo de alunos, sendo dois de cada ano escolar do ensino fundamental II, da Escola Estadual Getúlio Vargas, da cidade de Manaus, no Estado do Amazonas. A leitura sobre a história de vida e memória são pressupostos teóricos e metodológicos do ensino de arte a partir das narrativas que tomam como base os trabalhos de Hadna Abreu.

Hadna Abreu é uma artista amazonense que possui um trabalho autoral caracterizado por traçados leves e cores suaves que a técnica da aquarela Ihe proporciona. A cada temporada de apresentação dos seus trabalhos a artista reflete em suas obras maneiras diferentes de se expressar, trazendo à tona temas sensíveis como a velhice e sensibilidade, a exemplo do que expressou na sua primeira exposição intitulada "Linhas do Tempo", no ano de 2013. Dividimos este trabalho em três partes. Na primeira, se discute os conceitos que serão aplicados ao estudo e a proposta pedagógica. Na segunda parte, explana-se acerca da referência artista utilizada na proposta. E por fim, trata-se de apresentar apontamentos metodológicos para o desenvolvimento do processo criativo em kirigami no ensino das artes visuais.

O intuito da proposta de trabalho de pesquisa é que os alunos pratiquem a observação, o olhar para o não dito e sentir a narração das histórias de vida, deixando aflorar mais suas sensibilidades e criatividade, estreitando nesse processo os laços afetivos entre netos e avós (juventude e velhice).

\section{HISTÓRIA DE VIDAS E MEMÓRIA}

Para a discussão e proposta que objetivamos apresentar neste trabalho, faz-se necessário tecer algumas considerações sobre as histórias de vida, considerando que as mesmas abarcam duas ponderações que articulam a memória individual e memória coletiva, em um processo em que ambas são dependentes uma da outra para existir.

De acordo com Costa e Gonçalves (2016) a memória pode ser rica de detalhes quando as histórias são rememoradas. Nesse processo, "memória é tudo aquilo do que uma pessoa se lembra, como também a sua capacidade de lembrar" (COSTA; GONÇALVES, 2016, p. 126). Dessa forma, as memórias começam a ser contadas em forma de narrativa, que vão sendo organizadas de forma aleatória ou cronológica a depender do que as pessoas rememoram e selecionam como passagens mais significativas.

Assim, se a memória traz a tona imagens do passado, fisicamente, ela é o processo de aprender, armazenar e recordar uma informação. Memória não é história. A história é a narrativa que montamos a partir de nossa memória, a (re)construção do que lembramos. (COSTA; GONÇALVES, 2016, p. 127)

Nesse sentido, a proposta empreendida tem por objetivo resgatar memórias por meio de entrevistas dos alunos com os seus avós ou alguém que exerça essa figura simbólica. A ideia é fazer o registo dessas memórias, a partir das quais, os discentes desenvolverão uma narrativa através da criação de cenas em formas de desenhos e pinturas, tomando como referência os trabalhos e técnicas empregadas pela artista Hadna Abreu, na forma de um kirigami ${ }^{1}$. O que será expresso nos kirigamis será reflexo dos relatos de experiências de vida, que, de acordo com Larrosa (2002) é de cunho individual, muito embora o ser humano faça parte de uma 


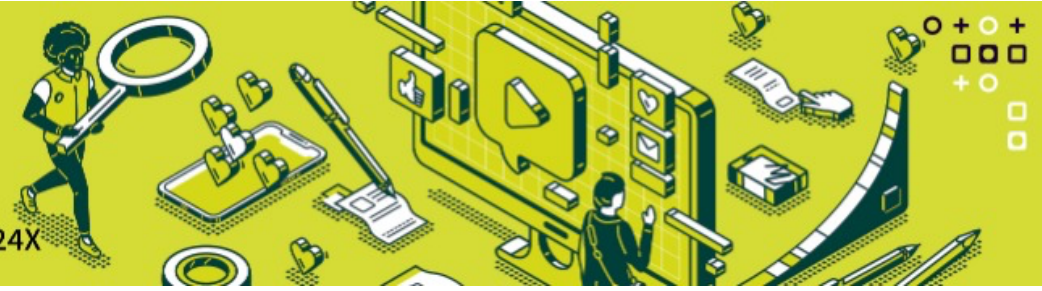

sociedade, mesmo passando pelos mesmos acontecimentos, a experiência de cada um será individualizada. Assim, Larrosa (2002) explicita

Se a experiência é o que nos acontece e se o saber da experiência tem a ver com a elaboração do sentido ou do sem-sentido do que nos acontece, trata-se de um saber finito, ligado a existência de um indivíduo ou de uma comunidade humana particular; ou, de um modo ainda mais explícito, trata-se de um saber que revela ao homem concreto e singular entendido e individual ou coletivamente, o sentido ou o sem-sentido de sua própria existência, de sua própria finitude. Por isso, o saber da experiência é um saber particular, subjetivo, relativo, contingente, pessoal (...) o acontecimento é comum, mas a experiência é para cada qual sua, singular e de alguma maneira impossível de ser repetida. (LARROSA, 2002, p. 27)

Desse modo, os alunos praticam a observação, o olhar para o não dito, sentindo e revivendo a narrativa enquanto a mesma se constrói, a partir das histórias de vida, deixando a sensibilidade trabalhar, pois as vivências que o aluno obtém o faz alcançar, no decorrer do processo, uma relação estabelecida com os aspectos da experiência humana e, por conseguinte, fomentar manifestações artísticas através de processos criativos. Assim, John Dewey (2010) enfatiza que:

A experiência ocorre continuamente, porque a interação do ser vivo com as condições ambientais está envolvida no próprio processo de viver. Nas situações de resistência e conflito, os aspectos e elementos do eu e do mundo implicados nessa interação modificam a experiência com emoções e ideias, de modo que emerge a intenção consciente. (DEWEY, 2010, p. 109)

De acordo Dewey (2010), a experiência é algo que adquirimos continuamente. Nesse sentido a experiência pode ser triste, divertida, odiosa, raivosa, dentre outros sentimentos que podem se expressar nas manifestações artísticas, trazendo a espontaneidade com a existência e vivência de valores, lembranças tanto passadas quanto atuais, aliando assim a sua personalidade.

$O$ ato da sensibilidade tem como essência uma formação de vida coletiva e essa conexão, de base semiótica, ou seja, os sinais e a simbologia estão muito presentes no nosso cotidiano e o contador dessas histórias carrega esses elementos para o ouvinte, para que as experiências de vida de cada um sejam ativadas novamente, como uma maneira de relembrar as suas memórias ou presentificar o passado. O ouvinte será capaz de ter suas próprias interpretações no que se refere a todos os campos artísticos e comuns do dia a dia.

\section{Obra de Hadna Abreu - linhas do Tempo}

A exposição de Hadna Abreu, artista amazonense, intitulada "Linhas do Tempo" que ocorreu em meados do ano de 2013, sob a curadoria de Turenko Beça², apresentou aproximadamente vinte e cinco ilustrações que foram exibidas na Galeria do Largo de São Sebastião, situada na cidade de Manaus, no Estado do Amazonas. A exposição foi aberta ao público gratuitamente, incluindo todas as faixas etárias. A artista tinha 24 anos de idade quando realizou a essa exposição individual "Linhas do Tempo" ${ }^{3}$, composta por ilustrações em quadros, esculturas e pinturas nas paredes. A artista comentou que o projeto foi desenvolvido por meio de linhas de expressão nas obras, fazia uma relação com o processo de envelhecimento 4 .

A mostra que inicialmente estava prevista para ser inaugurada no mês de abril, ocorreu no mês de julho, em virtude da troca da administração da Galeria do Largo. Nesse intervalo de tempo, a artista aproveitou para trabalhar em novas peças, que foram incluídas na exposição. Assim, uma dessas peças produzidas, foi a escultura que tem a altura de uma pessoa adulta idosa, com dimensões de tamanho real (Figura 1). As 


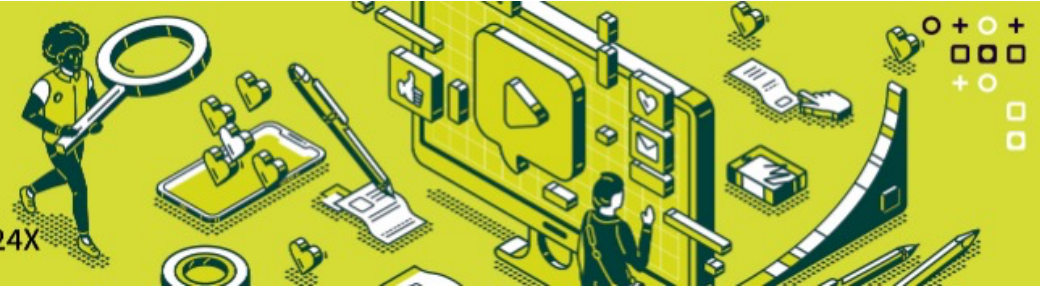

ilustrações em quadros são pintadas em aquarelas e desenhadas com nanquim. Já as ilustrações nas paredes, eram pintadas com tinta acrílica, a partir da técnica de tinta aguada.

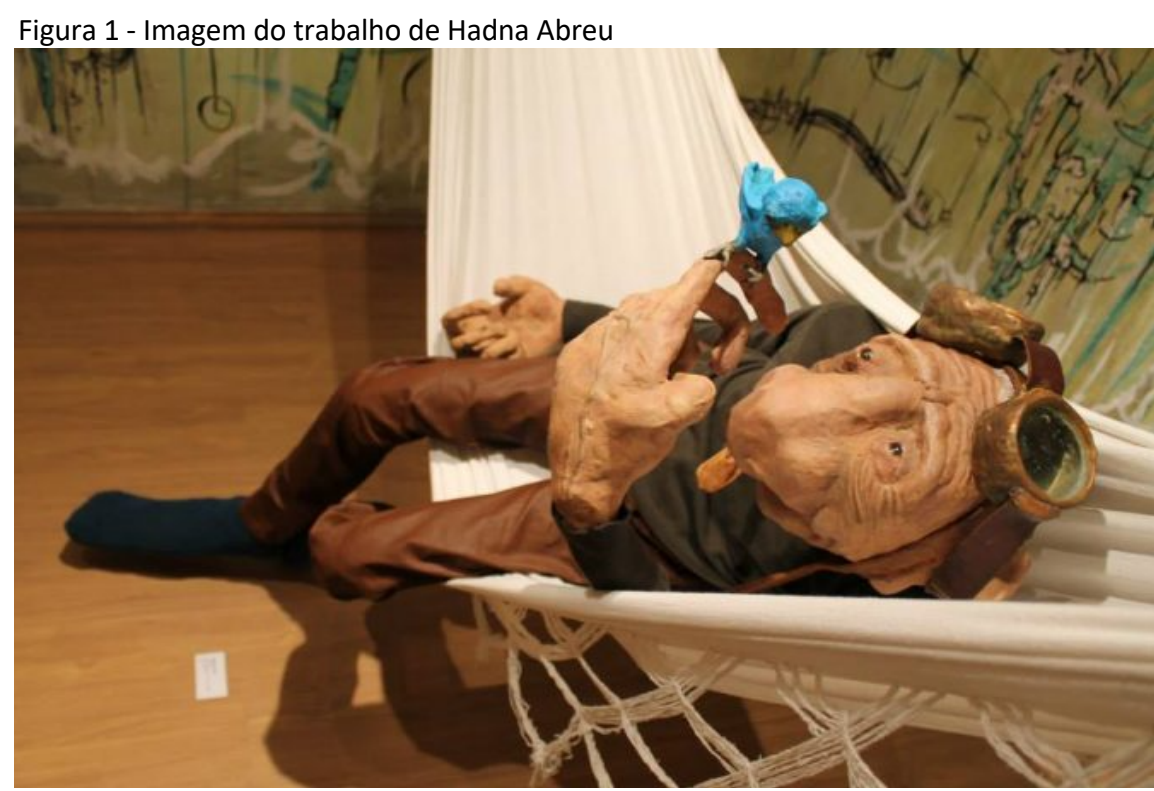

Fonte: https://vivamanaus.com/2020/11/18/exposicao-linhas-do-tempo-de-volta-para-casa

De acordo com os relatos do curador da exposição, as peças que foram expostas prometiam impressionar o público, independente da faixa etária. A artista se vale de linguagens inclusas na arte urbana contemporânea, porém com características sensíveis e delicadas, que não se restringem ao grafite e que ao mesmo tempo, mexe e sensibiliza as emoções das pessoas. Para Turenko Beça $a^{5}$ podemos perceber influências diversas, tais como: em Brian Froud, ilustrador que tem em suas obras o recurso da fantasia através de fadas, duendes; Margareth Mee, uma artista/ilustradora botânica inglesa, que se especializou em plantas da Amazônia brasileira e que utiliza guache; Pollock, pintor norte-americano com referência no movimento do expressionismo abstrato e pela utilização da aquarela; Salvador Dalí do surrealismo apresentando seu mundo surreal e Otoni Mesquita professor aposentado da UFAM com seus trabalhos em aguadas.

Portanto, essa artista utiliza os mais diversificados materiais e tem apreço pelo papel, que segundo ela, caracteriza-se como seu suporte principal, seja em posters lambe-lambe e em papeis mais robustos e de maior gramatura. "Linhas do tempo" tem como referências principais os seus avós, fazendo uma relação com o processo de envelhecimento que se torna perceptível na ênfase das linhas de expressão bem marcadas dos sujeitos representados em suas obras.

Em entrevista ${ }^{6}$ realizada pela monitoria da Galeria do Largo, antes da exposição ser aberta ao público, a artista informou que já trabalhava com a temática do idoso há aproximadamente dez anos. Para a artista, a intencionalidade era expressar, por meio de suas criações a alegria, a beleza e o futuro que essas pessoas ainda podem ter. Nas suas obras, se destacam caricaturas de anciãos animados, mostrando um lado mais descontraído e sensível, onde mesmo com suas limitações corporais, podiam expressar a beleza da vida. Para a Hadna, a intencionalidade também é mostrar aos jovens que para a conquista da felicidade, basta estar aberto à cumplicidade e ao respeito aos mais velhos, aliando essa aproximação a simplicidade. O trabalho da artista se destaca por sensibilizar o público e provocar reflexões sobre o nosso olhar sobre a velhice. As obras expostas remontam memória e experiências vivenciadas pelos avós (Figura 2) da artista, delineando as histórias de vida desses sujeitos a partir da seleção de momentos considerados significativos. 


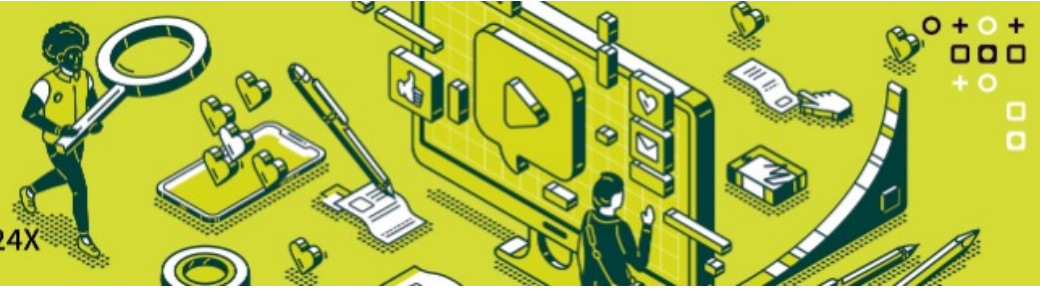

Figura 2 - Figura 2. Pintura de sua avó na parede da galeria.

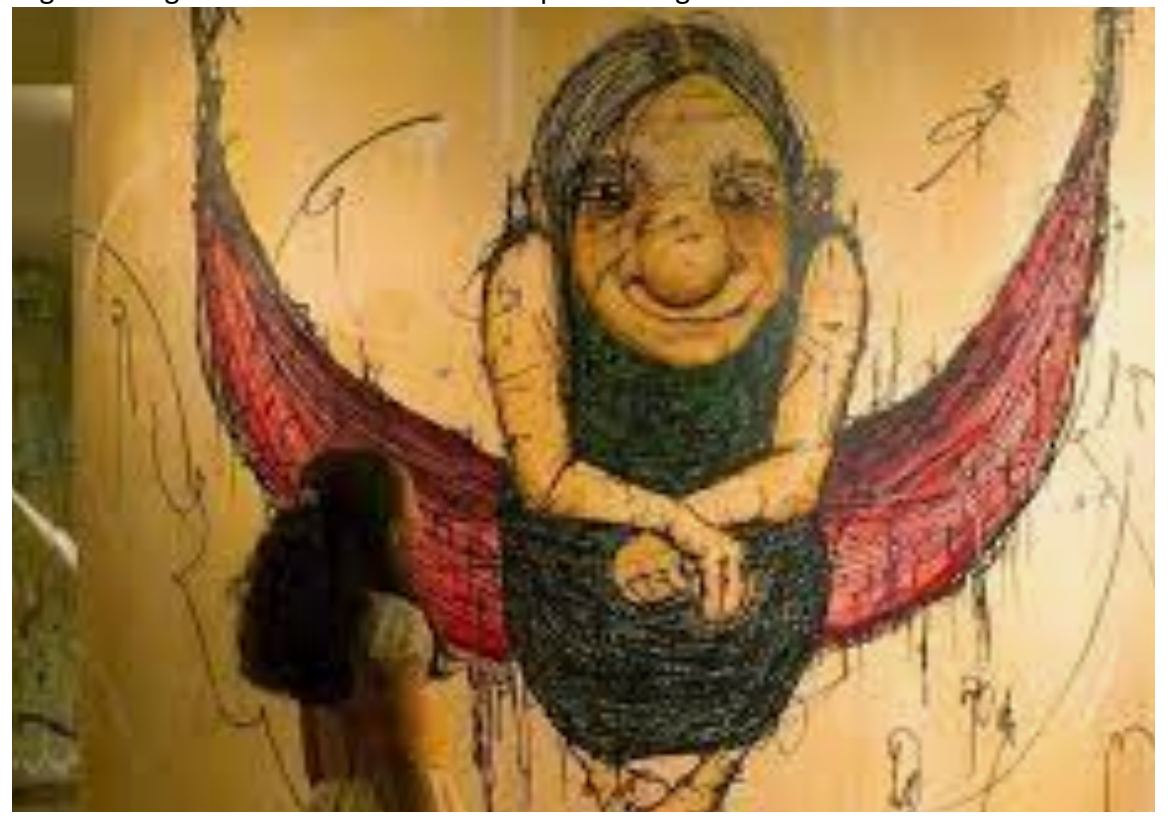

Fonte: https://portalamazonia.com/estados/amazonas/hadna-abreu-estreia-novaexposicao-linhas-do-tempo-de-volta-para-casa

É perceptível nas obras que a artista retratou o que vinha a sua memória, dando ênfase a uma produção memorialista. Nesse sentido, era costume retratar a sua experiência com os avós em linhas simples como se fossem rabiscos. Desse modo, os trabalhos apresentam uma relação íntima com a família e principalmente com avós. A leveza, a sensibilidade e a velhice são sua marca. Essa sensibilidade trabalha por si só, despertando no observador o sentir, criando conexões humanas em tempos de liquidez das relações.

\section{Apontamentos Metodológicos para uma Proposta Pedagógica em Artes Visuais}

Para a proposta pedagógica no âmbito da pesquisa de mestrado, propõe-se um experimento em que os discentes interajam com seus avós e por meio de entrevistas, realizem um levantamento das experiências narradas e interpretem essas histórias em obras artísticas, utilizando anotações, transcrições e ilustrações com o intuito de presentificar essas memórias contadas por seus avós. John Dewey (2010) é base para essa abordagem metodológica que fundamenta esse tipo de experimentação, bem com, Mike Baxter (2000), Sandra Rey (2002), Camila Serino Lia (2012) e Ana Mae Barbosa (2014), que referenciam as demais etapas do processo criativo a ser desenvolvido pelos alunos na criação de kirigamis.

O processo criativo se desdobrará em etapas, onde de forma preliminar, serão fornecidas informações para que os estudantes conheçam a vida e obra da artista, bem como as características que delineiam sua identidade, as técnicas empregadas e as influências artísticas, especialmente aquelas que aparecem na exposição escolhida como referência. Sob orientação, os alunos farão uma análise das obras expostas, para identificar formas, cores, texturas, materiais utilizados e as temáticas trabalhadas pela artista, com destaque as obras da exposição, bem como as técnicas utilizadas pela artista que são as aguadas em tinta acrílica e tinta aquarela.

Concomitantemente, os alunos deverão fazer anotações e captura de imagens sobre a vida e obra da artista para servir de referencial na pesquisa e do processo criativo individual. Para os alunos participantes da pesquisa será disponibilizado textos imagens sobre o contexto histórico de vida e obra da artista utilizando o aplicativo "WhatsApp". Todas essas atividades têm como objetivo fazer com que o aluno comece a criar um 


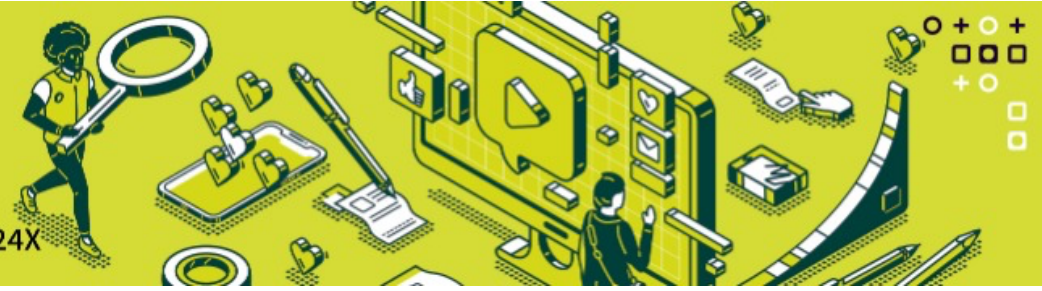

referencial artístico e pensar no seu processo criativo. Nesse processo, serão trabalhados conceitos como velhice e memória objetivando uma reflexão sobre as interações entre gerações. Por meio de entrevistas com os avós os alunos terão a oportunidade de se aproximar das trajetórias de vida desses sujeitos, estreitando os laços entre as gerações. Lia (2012), tomado como referência Nóvoa (1992), propõe um caminho para a organização dessas narrativas. A autora aponta:

(...) como proposta para organizar a narrativa, Nóvoa sugere um determinado eixo de investigação, que impediria, segundo o autor, certa "derrapagem" ou "pendor psicanalítico" na abordagem biográfica. (...) Esses eixos transcritos do autor seriam:

- Estruturação e ciclos - entendida como a globalidade de um percurso de vida, será que a biografia educativa permite detectar etapas, momentos formadores, pontos de ruptura, fases de transição, ciclos, que modificam e estruturam as relações do saber e à atitude face à profissão?

- Mapa das relações - Que pessoas influenciam a trajetória de vida, que desempenham o papel importante no itinerário intelectual ou na concepção de vida profissional? Essas pessoas acompanham todo o percurso de vida, ou intervém apenas num dado momento? Elas são sempre reais, ou, por vezes, são também imaginários?

- Espaços e meios sociais - Cada pessoa constrói-se ao saber de contextos sociais, de universos simbólicos ligados a organizações (escolares, religiosos, etc) e locais (rurais e urbanos). Esse meio físico e social desempenha um papel formador? Quando e como? Esses espaços de vida forjam a representação que nós temos da realidade? De que modo?

\begin{abstract}
- Percurso escolar e educação não-formal - O percurso escolar imprime uma certa orientação à vida de cada um: de que forma esse percurso se articula com outros espaços educativos (família, grupos de jovens, experiências de vida, etc)? O que ficou da escola após vários anos de vida social e profissional? Onde se faz a "educação" que não concede diplomas, nem certificados? Qual a relação entre a educação formal e a educação não formal?
\end{abstract}

- Formação Contínua e origem social - O nosso percurso escolar e profissional está ligado à nossa origem social: de que modo encaramos as ações de formação contínua e/ou de educação permanente? Quais são as razões que nos levam a querer ultrapassar em nível de formação de base e a querer ir mais longe do ponto de vista cultural e acadêmico? Qual é a nossa cultura de base e de que modo evolui o nosso universo cultural? (LIA, 2012, p. 28)

O processo de seleção dos alunos deve ocorrer de maneira sistematizada, como forma de identificação preliminar das habilidades artísticas nas turmas do ensino fundamental II. Serão selecionados 2 (dois) alunos por série, do 60. ao 9․ Anos, totalizando 8 alunos. Os alunos selecionados para fazer parte da ação poderão utilizar fotografias, desenhos, pinturas, frases soltas bem como o uso de elementos que eles avaliem significativos no álbum, com a intenção de exercitar o processo criativo.

As atividades utilizadas para identificar a habilidade desses alunos foram feitas com temáticas de acordo com a programação do Aula em Casa ${ }^{7}$ feita e elaborada pela SEDUC-AM, referente a este ano de 2021, desde quando se iniciou as aulas híbridas (presencial e remota).

As temáticas dessas aulas remotas em que se considere pertinentes serão solicitadas atividades práticas, como desenhos e pinturas. Conforme os alunos forem entregando os prints das atividades por meio do aplicativo WhatsApp, iniciam-se as seleções dos trabalhos mais destacados, seja pelo traçado, expressão visual, rabiscos ou pinturas. 


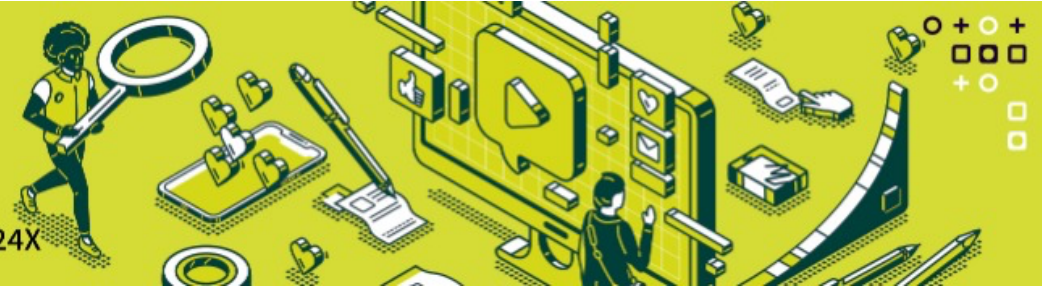

Com os alunos selecionados e as referências teóricas e artísticas trabalhadas, partiremos para a próxima etapa, onde serão feitas as idealizações dos desenhos, pinturas, a partir dos seguintes questionamentos: Qual seria a melhor técnica? Quais materiais a utilizar? Qual melhor acabamento do álbum (kirigami)?

A etapa seguinte será a coleta das memórias dos avós por meio da realização de uma entrevista estruturada previamente. Realizada a coleta, os alunos serão reunidos em uma roda de conversa para a discussão das histórias levantadas e, por conseguinte, a escolha das ideias para a criação de seus trabalhos. Baxter (2000) aponta que

A geração de ideias pode ser mais efetiva quando: 1) houver um período de preparação para absorver e digerir as informações disponíveis; 2) as ideias forem geradas com o máximo de imaginação e criatividade possíveis; e 3) a melhor ideia for selecionada, em comparação com os critérios estabelecidos no início do processo. (BAXTER, 2000, p. 65)

Semelhantemente Rey (2002), em sua abordagem metodológica para a realização de processos criativos em artes visuais, aponta a existência da dimensão abstrata que "processa-se no nível do pensamento e revela-se na forma de ideias, de esboços, muitas vezes sem grandes intenções, em algumas anotações improvisadas ou em projetos mais elaborados, que poderão, ou não, se concretizar em obras" (REY, 2002, p. 126).

Enfatiza-se que a intenção não é produzir cópias das obras da artista de Hadna Abreu e sim promover releituras com base nas obras de Linhas do Tempo da artista. A este respeito Martins (1994) citando Pillar (2011) considera que há uma grande distância entre releitura e cópia. A cópia diz respeito ao aprimoramento técnico, sem transformação, sem interpretação, sem criação. Já na releitura há transformação, interpretação, criação com base num referencial, num texto visual que pode estar explícito ou implícito na obra final. Aqui o que se busca é a criação e não a reprodução de uma imagem.

A partir da exibição das imagens referentes as obras da artista, os alunos irão analisar os traçados, as linhas, as técnicas empregadas e posteriormente passar pela experiência da técnica da aguada com aquarela e pintura aguada com acrílica, sobreposições e texturas, a partir da utilização dos seguintes materiais: Lápis 2B, 4B, 6B, borracha, papel toalha, apontador, tinta aquarela se possível (Pentel), pincéis de pelos macios e grossos, papel de gramatura alta, específico para aquarela de preferência (Canson), tinta acrílica da (acrilex) para pintura em tela: nas cores primárias amarelo, azul e vermelho, preto e branco (tubinhos ou pote), papel cartão, fita dupla face, papel A4, canetas coloridas, E.V.A.

Além da técnica utilizada pela artista referente, será proposto o uso de outras técnicas como: o desenho em grafite, lápis de cor, pincel atômico, pinturas texturizadas, dentre outras, sem perder o foco na temática abordada pela artista, bem como traços e cartela de cores. Vale ressaltar, que nesse contexto de pandemia, a opção sempre será a escolha e uso de materiais que os alunos já tenham em casa, evitando assim a circulação e o contado com outras pessoas.

Nessa etapa portanto, os alunos farão vários esboços, ou seja, vários estudos de técnicas, irão treiná-las e quando eles acharem que estão prontos para passá-las para o definitivo assim o farão. As gerações de alternativas irão ser divididas em partes: Material e Acabamento, com a elaboração de esboços sugeridos como estudos, para verificar, por sua vez, como a ilustração se comportaria anexa no álbum. A finalidade é selecionar dentre estas tentativas, os melhores esboços e por fim escolher os desenhos definitivos para compor o kirigami (Figura 3). 

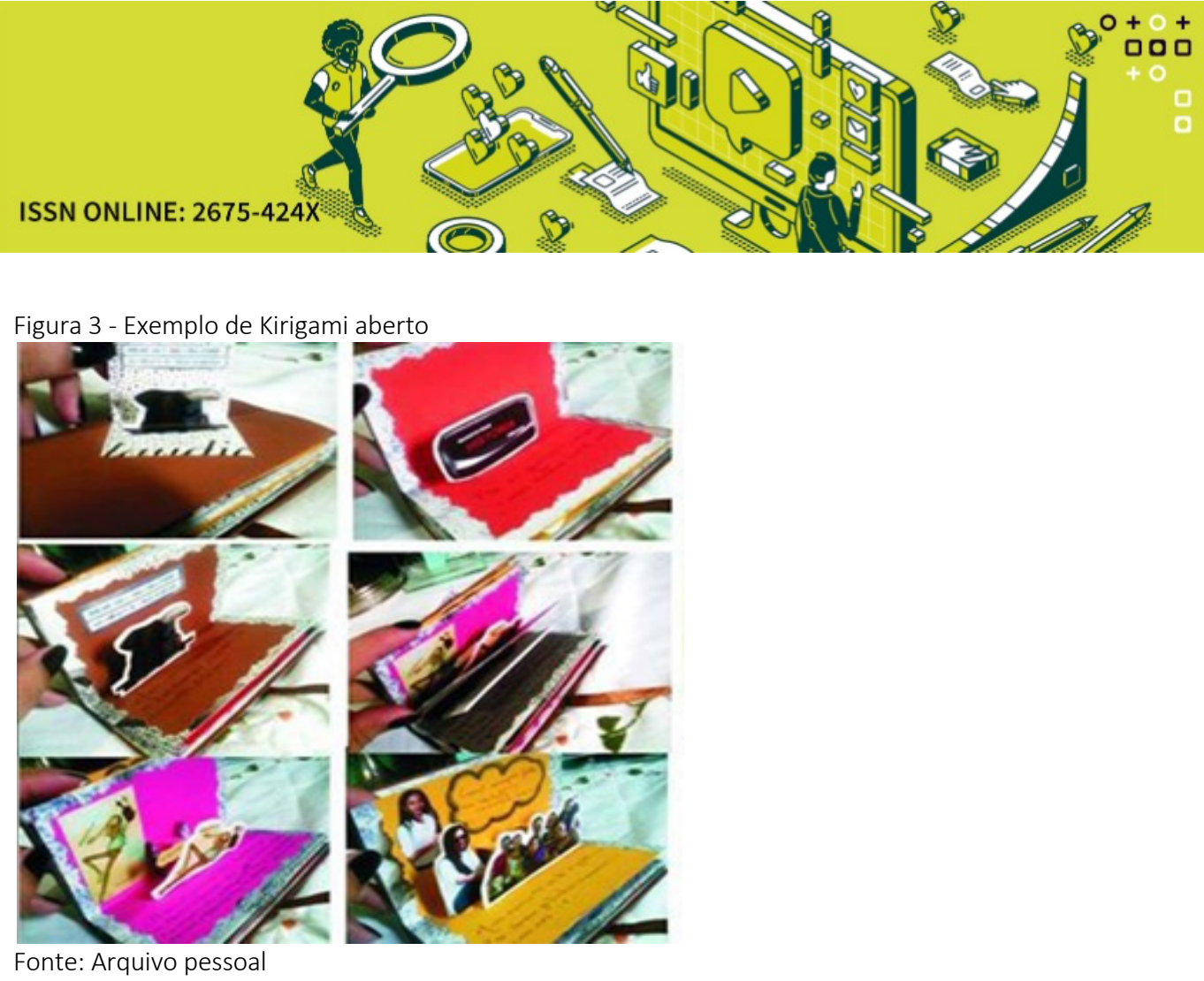

Todo o processo criativo será sob orientação, por meio de um passo a passo, com intuito de estimular o desenvolvimento das atividades principalmente em aspectos como: criatividade; habilidades motoras finas; habilidades motoras visuais e planejamento. Com o rascunho feito pelos alunos, os alunos irão deliberar como preencherão os espaços do álbum e de qual maneira irão esboçar e colorir essas memórias, que materiais irão utilizar e que local vão anexar essas imagens. Depois de muitos estudos e tentativas, os alunos irão adquirir a prática e a familiaridade com o desenho e suas técnicas escolhidas. Para se obter ótimos resultados, os alunos terão que fazer vários esboços e tentativas, por isso o significado da frase a perfeição vem da prática. 0 processo de construção do kirigami se dará de forma gradual, a ser construída página por página. Ao definirem e finalizarem cada página, os alunos irão unir uma página na outra, dando forma ao corpo da "boneca" ${ }^{8}$ (Figura 4).

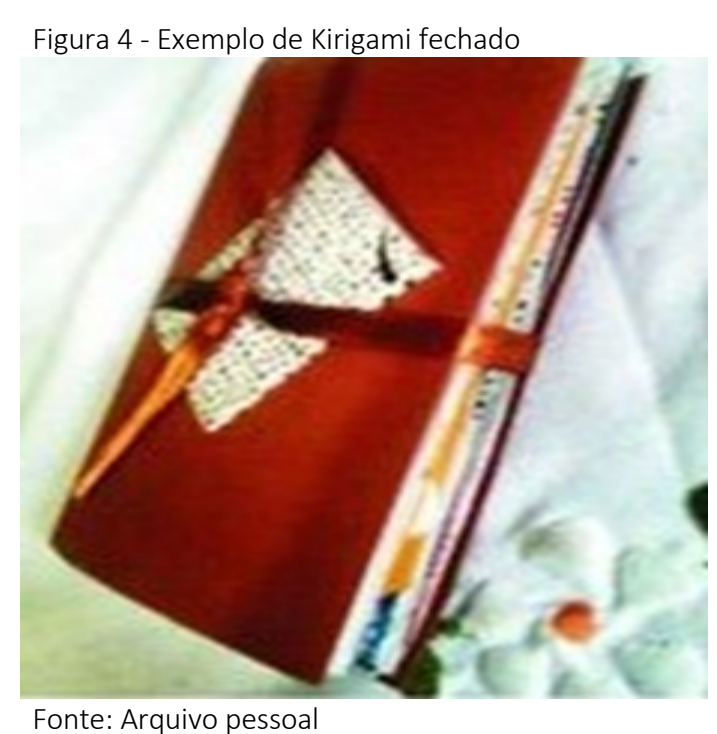

Portanto, a proposta pedagógica, foi a ideia é expressar artisticamente memórias expressivas de seus entes queridos, a partir do exercício de várias tentativas, esboços com diversos materiais, para então verificar e 


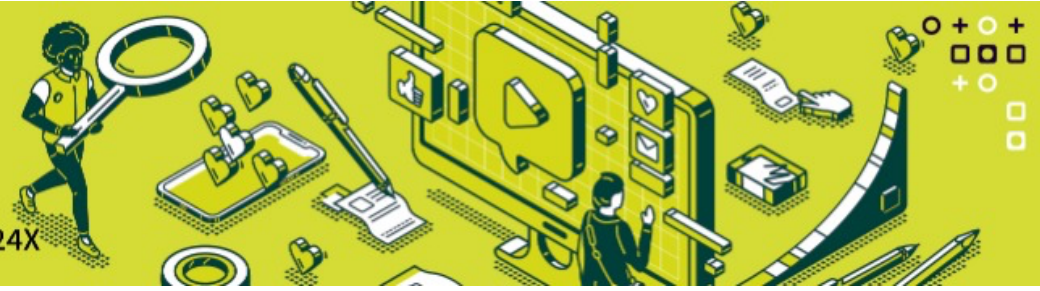

selecionar a melhor forma, técnica e acabamento a ser utilizada nos trabalhos e por fim expor o álbum numa apresentação com a finalidade de mostrar ao observador relatos e expressão dessas memórias por meio das artes, construindo assim, uma narrativa visual em forma de kirigami.

\section{CONSIDERAÇõEs FINAIS}

O foco de interesse da pesquisa é articular teoria e prática no processo de ensino e aprendizagem, a partir da releitura das obras da artista amazonense Hadna Abreu, caracterizada por traçados leves e cores suaves. Trabalhando aspectos como vida e obra da artista, bem como seu contexto histórico, servindo de referente para a elaboração de criações próprias dos alunos a partir das obras dessa artista que trabalha a temática da velhice e a sensibilidade.

A ação proposta objetiva desenvolver a empatia, estimulando um olhar que se preocupa com o outro, bem como a relação entre as gerações, propiciando as trocas entre jovens e idosos, consiste em promover um momento de interação dos jovens com seus entes queridos. Nesse sentido, essa interação se manifestará em rabiscos, desenhos, pinturas, colagens que vão compor um álbum autoral onde se demonstra o uso de diferentes técnicas, mas que mantem a coerência com identidade da artista referente expressada nas cores, nos traçados, nas sobreposições e o despertar das emoções expressada nas artes.

Portanto, a ideia central da aplicação da proposta pedagógica é o resgate dos laços entre os jovens e idosos, a partir da interpretação das narrativas que os alunos construirão com base nas memórias e nas experiências de seus avós ou familiares mais velhos. Ao final do processo de trabalho, com o kirigami finalizado, os alunos estarão aptos para apresentar suas experiências, que por sua vez, será exposta ao público.

\section{REFERÊNCIAS}

ABREU, Hadna. Vida e Influências de Hadna Abreu. [Entrevista concedida a Daizyenne Silva]. Monitora da Galeria do Largo em 27 de Maio de 2013.

BARBOSA, Ana Mae. A imagem no ensino de arte. São Paulo: Perspectiva, 2014.

BAXTER, Mike. Projeto de produto: Guia prático para o design de novos produtos, 2ªed. Editora: Edgard Blucher Itda, 2000.

CALDAS, Priscila. Hadna Abreu apresenta a mostra 'Linhas do Tempo'. Jornal Em Tempo. Manaus, ano 2013 p.D3, 27 de junho de 2013.

COSTA, Roseli Araújo Barros; GOLÇALVES, Tadeu Oliver. HISTÓRIAS DE VIDAS: A VEZ E A VOZ DOS PROFESSORES. Margens, [S.I.], v. 7, n. 8, p. 137-154, may 2016. ISSN 1982-5374. Disponível em https://periodicos.ufpa.br/index.php/revistamargens/article/view/27 Acesso em 03 jun. 2021.

DEWEY, John. Ter uma experiência. In: DEWEY, J. Arte como experiência. p. 109-141. São Paulo: Martins Fontes, 2010.

LARROSA BONDÍA, Jorge. Notas sobre experiência e o saber da experiência. In Revista Brasileira de Educação. Jan/Fev/Mar/Abr de 2002, n.19.

LIA, Camila Serino. Experiências de educadores: convite para reflexão sobre a formação contínua. Dissertação Programa de Pós-Graduação em Artes da UNESP Área de concentração: Artes e Educação Linha de Pesquisa: Mediação cultural: histórias, políticas, metodologias. São Paulo, 2012

MARTINS, Maria Helena. O que é leitura. São Paulo. Brasiliense, 1994.

NÓVOA, Antônio (org). Vidas de Professores. Portugal: Porto Editora, 1992.

PILLAR, Dutra Analice. A educação do olhar no ensino das artes. 6ạ. Ed - Porto Alegre: Mediação, 2011. 
REY, Sandra. Por uma abordagem metodológica da pesquisa em artes visuais. In: BRITES, Blanca; TESSLER, Elida (orgs.). O meio como ponto zero: metodologia da pesquisa em artes plásticas. Porto Alegre: Ed. Universidade/UFRGS, 2002.

\section{Sites}

Exposição Linhas do Tempo de volta para casa. Hadna Abreu. Disponível em: https://portalamazonia.com/estados/amazonas/hadna-abreu-estreia-nova-exposicao-linhas-do-tempo-de-voltapara-casa. Acesso 08/06/2021

Turenko Beça. Pequena biografia. Galeria do Largo. Disponível em: http://galeriadolargo2008.blogspot.com/2008/04/turenko-bea.html. Acesso 08/06/2021

\section{Notas}

${ }^{1}$ Kirigami trata-se da arte de cortar papel dobrado, que por sua vez difere da técnica do origami, em que se dobra o papel sem cortá-lo. O kirigami apresenta infinitas possibilidades que pode se expressar em uma simples arte decorativa a uma complexa escultura. Na ação interventiva proposta, o kirigami dará forma a um álbum.

${ }^{2}$ Artista amazonense, Aníbal Augusto Turenko Beça, mais conhecido como Turenko Beça, faz parte da quarta geração de artistas plásticos do Amazonas, representando o Estado em eventos nacionais e internacionais. Desde 1992 realiza uma pesquisa antropológica sobre sociedades indígenas, de onde saíram suas principais exposições.

${ }^{3}$ Jornal Em tempo, Manaus, quinta feira, 27 de junho de 2013 - Sessão Plateia D3.

4 "Linhas do Tempo. Folder da exposição de Hadna Abreu, Galeria do Largo. Secretaria de Cultura. 2013.

5 "Linhas do Tempo. Folder da exposição de Hadna Abreu, Galeria do Largo. Secretaria de Cultura. 2013.

${ }^{6} \mathrm{Na}$ época em que a exposição foi realizada no ano de 2013, fazia parte da monitoria da Galeria do Largo, o que me possibilitava ter acesso aos artistas que expunham seus trabalhos neste espaço. Antes da exposição ser aberta ao público era feito uma entrevista com os artistas de modo a produzir um release sobre as obras com a finalidade de instrumentalizar os monitores que iriam fazer a visita guiada das exposições. Informa-se que o Release sobre a vida e influências de Hadna Abreu foi feita via relato dada por Hadna Abreu para as monitoras da galeria em 27 de maio de 2013 ${ }^{7}$ Como medida de enfrentamento à propagação do novo coronavírus (Covid-19) no Amazonas, o Ano Letivo 2021 das redes estadual e municipal inicia, no dia 18 de fevereiro, com o retorno do "Aula em Casa".

O projeto, que foi distribuído a 12 estados brasileiros, em 2020, consiste na transmissão de videoaulas pela TV aberta e internet. A iniciativa visa dar continuidade às atividades letivas, garantindo uma educação de qualidade e preservando a vida de toda a comunidade escolar.

O conteúdo curricular foi reorganizado para atender às necessidades dos alunos em cada nível, etapa e modalidade de ensino da Educação Básica.

${ }^{8}$ Esboço que dá uma ideia do aspecto que terá uma publicação ou qualquer outro trabalho gráfico, depois de impresso. Mostra o conteúdo e a disposição das páginas, servindo depois para orientar a montagem da edição. 